\title{
Dynamics of Shifting Viewpoints: An Investigation into Users' Attitudes towards Products
}

\author{
Georgi V. Georgiev* \\ Center for Ubiquitous Computing, University of Oulu, Oulu, Finland; \\ Email: georgi.georgiev@oulu.fi \\ *Corresponding author
}

\section{Kaori Yamada}

Organization for Advanced and Integrated Research, Kobe University, Kobe, Japan; Email: kyamada @mech.kobe-u.ac.jp

\section{Toshiharu Taura}

Integrated Research Center, Kobe University, Kobe, Japan;

Email: taura@kobe-u.ac.jp

\begin{abstract}
This study focuses on how products are viewed by their users. In order to capture users' viewpoints, we focused on how the virtual 3D model of a product was examined (rotated/translated/moved by the user). We attempt to understand these viewing mechanisms by focusing on the dynamics of shifting viewpoints and verbal features during the generation of product impressions. The notion of dynamics of shifting viewpoints in this study refers to changes between 'still viewpoints' and 'moving viewpoints'. If, in a given period when product impressions are generated, a viewpoint does not change, it is defined as a still viewpoint, whereas a moving viewpoint refers to shifts in the ways in which the products are viewed during a given period. The notion of verbal features involves the quantitative characteristics of verbalisations. The findings from an experimental observation show that the dynamics of shifting viewpoints, verbal features, and user's preferences are related.
\end{abstract}

Keywords: product experience, user experience, human behaviour in design, dynamics of viewpoints, shifting viewpoints, user impressions, user preferences, product design, think aloud, protocol analysis

Reference to this paper should be made as follows: Georgiev, G.V., Yamada, K. and Taura, T. (xxxx) 'Dynamics of Shifting Viewpoints: An Investigation into Users' Attitudes towards Products', J. Design Research, Vol. xx, No. x, pp. $x x x-x x x$.

Biographical notes: Dr. Georgi V. Georgiev is a docent and a senior research fellow at the Center for Ubiquitous Computing, University of Oulu. His research interests are in design creativity, digital fabrication and prototyping, design thinking, user interaction and experience, and design cognition. His research is focusing both on early stage of design process, when the new and innovative ideas are generated, and user's perspective on the design outcome, which is essential for understanding challenges for success of digital technologies. He holds a $\mathrm{PhD}$ in knowledge science from Japan Advanced Institute of Science and Technology. 


\section{G. V. Georgiev, K. Yamada and T. Taura}

Kaori Yamada is an assistant professor in the Organization for Advanced and Integrated Research at Kobe University, Japan. She received her degree of Doctor of Engineering from Kobe University in 2011. She stayed at TU Delft as a visiting researcher for a period of 10 months, during 2014-2015. Her research is in an interdisciplinary field that spans engineering, cognitive science, and computer graphics. She is particularly interested in understanding the expansion of new design ideas and in supporting this expansion of the design ideas using computers. Currently, she is investigating the methods of using virtual reality (VR) for designs, such as considering the scenes where products will be used by using VR, to create innovative products and visualizing concept networks using VR in order to deeply understand the nature of design knowledge.

Toshiharu Taura is the director of Integrated Research Center, and a professor for the Mechanical Engineering Department at Kobe University. After starting with a focus on engineering design, he went on to capture the general terms of design, with a particular interest in industrial design, art, technology, and cognitive science. He is a key figure in the Design Creativity academic field and has led interdisciplinary discussions on this topic. In 2007, he founded the Design Creativity Special Interest Group as part of the Design Society, and organized the First International Conference on Design Creativity in 2010 in Kobe, Japan. He also launched the International Journal of Design Creativity and Innovation in 2013, and serves as its editor-in-chief.

\section{Introduction}

User attitudes towards, preferences for, and impressions of products are essential in the current environment with so many excellent products available. Insights into these are important for the generation of design ideas, new product designs, and their future success. The premise of this study is that we can understand the mechanism of user preferences and impressions of products by focusing on the way the products are viewed. We refer to the way a product is viewed by a user as a viewpoint of a product. Originally, viewpoint related to space. Although it may seem counterintuitive, in this study we expand this original notion of viewpoint from space to time.

\section{1. 'Where' versus 'how' users' eyes and attention are focused on a product}

Exploring viewpoints in terms of time, we focus on the perspective of 'how' products are viewed. In order to capture the viewpoints, we focus on how the virtual 3D model of a product is examined (moved by the user). By observing the manner in which the subject rotates/translates/moves a virtual 3D model (product), we can gain deeper insights into the viewpoints and their role in the mechanism of user preferences and attitudes towards products (e.g. how viewpoints are moving, when viewpoints are moving, and when they are not moving). The originality of this exploratory study comes from this focus and the methodology developed to investigate this perspective. Previous studies have concentrated on viewpoints from the perspective of 'where' (on which part of the product) the users' eyes are focused at any given moment. 


\section{Dynamics of Shifting Viewpoints}

\subsection{Previous works}

Different theories relate to the mechanism of attitudes towards, preferences for, and impressions of products.

The formation of preferences, attitudes, and impressions is built on affective judgements preceding further perceptual and cognitive operations (Zajong, 1980). Affect and cognition influence each other, but they also represent independent sources of information processing. Objects have to be cognized before they can be evaluated (Zajong, 1980). The consumer needs to 'meet' the product and have an experience; subsequently, the consumer needs to 'process' his/her experience to communicate about the product or object (Haug, 2015). An investigation of design interactions that evoke user interest is based on the appraisal theory, and points that interest emerge from a combined appraisal of novelty-complexity, and coping potential (Yoon, 2010). Furthermore, there is a relationship between novelty and aesthetic preference (Hung and Chen, 2012).

The cognitive dissonance theory is applied to investigations regarding differences in behaviour and cognition (Festinger, 1957; Harmon-Jones and Harmon-Jones, 2012) and describes dissonance and consonance in terms of cognition-related to opinions, beliefs, knowledge of the environment, and knowledge of one's own actions and feelings. Cognitive inconsistency introduces discomfort and motivates cognitive and behavioural changes (Harmon-Jones and Harmon-Jones, 2012; Junaidy et al., 2015). Regarding attitudes towards products, this means that if a given product reflects consonance (i.e. reduced cognitive inconsistency) with users' opinions, beliefs, and knowledge, users may have positive attitudes towards, preferences for, and impressions of the particular product.

Product character as perceived by the user is a major dimension of product experiences, and 'the intended product character' and 'the character perceived by the user' are used to describe congruency of experiences (Bongard-Blanchy et al., 2015). Attitude formation is important here because it shapes a user's perceptions (Albarracin et al., 2008). Perceptions refer to associations between an object or product and an evaluative category such as good or bad; perceptions are explicit or implicit. On one hand, explicit attitudes are commonly measured with scales. On the other hand, implicit attitudes are formed gradually through experiences and learning (Albarracin et al., 2008). Aesthetic appreciation in art has been examined on the basis of variables such as novelty, complexity, ambiguity, uncertainty, or surprise (Berlyne, 1971) and by exploring the relationship between human cognitive and emotional capacities. These variables have accounted for an individual's interest in and reactions to diverse forms of stimulation. The 'elementarist' approach allows more complex stimuli to be devised for modelling (artistic) objects, given an understanding of their components. The 'holistic' approach begins with an intact (artistic) object or experience, regardless of its complexity. It is possible that a more accessible design makes a difference in which products are liked or disliked (Coates, 2002).

Mental imagery refers to quasi-sensory or quasi-perceptual experiences that a human is aware of; it exists in the absence of stimuli (Richardson, 2013). Mental imagery is consistently highest for vision sensory modality (Schifferstein, 2009). The user's way of viewing a product may influence the mental imagery experience associated with the product. In order to create a long-lasting positive product experience, designers need to consider user-product interaction at different stages of product usage. At the time of 


\section{G. V. Georgiev, K. Yamada and T. Taura}

purchase, vision is the most important sensory modality for product design (Fenko et al., 2010).

In line with attentiveness regarding where users' eyes focus when looking at a product, previous works apply empirical frameworks focused on operation, function, and other aspects. Furthermore, frameworks have been applied to both users' and designers' standpoints (Figure 1).

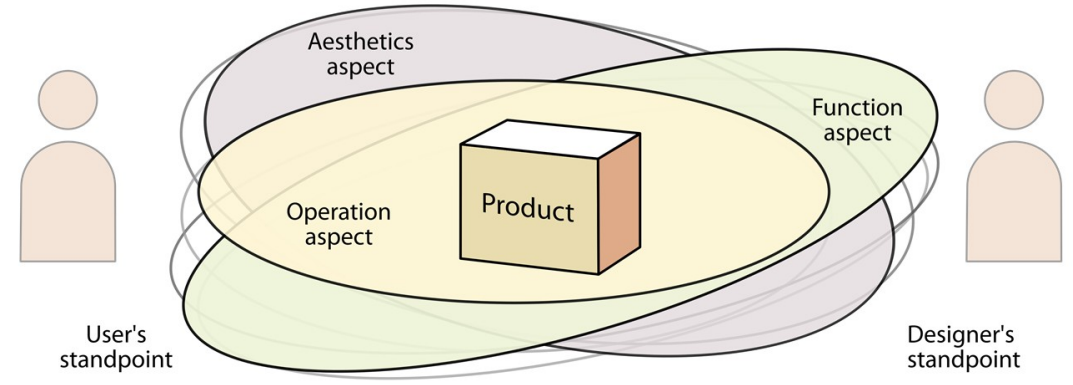

Figure 1. Standpoints and aspects.

A common approach to investigate where users' eyes are directed when looking at a product is the tracking of movements and fixations of subjects' eyes (i.e. eye tracking) (Poole and Ball, 2006). Regarding the users' standpoint, a number of previous studies on users' viewpoints investigated operational aspects. Eye tracking has been used as an approach to capture the specific product parts on which users are fixated or focused (Chen et al., 2007). In this study, fixations were investigated when a product was being used for specific operational tasks; in this case, a home appliance product was used. The results showed that physical properties and signage on a product played different roles in user operations. Based on the idea that innovative designs may break common visual habits, users' viewpoints on images of innovative vehicle interiors were investigated (Carbon et al., 2006). The analysis of eye movements indicated that innovative designs generated an increased number of eye movements directed at specific areas with balanced conceptual structures. Research on user viewpoints extends further by applying eye tracking to quantify the qualities of visual aesthetics in product design (Khalighy et al., 2015). Eye behaviour of users is related to the perceived qualities of appropriateness, novelty, and beauty.

From the designers' standpoint, an eye-tracking approach to identify engineers' (designers') viewpoints has been used in a case involving functions of an engineering system (Matthiesen et. al., 2013). The gaze data acquired from observing the behaviour of engineers who were analysing a drawing representation of a technical system was shown to be useful for investigating the acquisition of a functional understanding of a system (product). In addition to gaze (viewpoint), verbalisation data carry several advantages for research aimed at strengthening a functional understanding of technical systems and products. Moreover, strategies used by engineers in the analysis of a technical problem (a real-world, problem-solving task) have been investigated with eye tracking (Ruckpaul et al., 2014b). Accordingly, analyses of identified areas of interest (AOIs) and a sequence chart of eye fixations on these areas could be useful. In a broader sense, where designers' eyes are focused when examining a product has been investigated in terms of physical interactions during early-stage designing. The product dissection by a designer (i.e. taking apart or analysing all components of a product and 


\section{Dynamics of Shifting Viewpoints}

viewing them individually) affects design exploration and new ideas about designs (Toh and Miller, 2014). Physical interactions encourage more form-based novelty but less functional focus compared to visual inspection of a product. Designers' perceptions during sketching have been analysed with eye movements (Sun et al., 2014). The eye actions, along with brain and hand actions of designers, have been analysed as sequences and comprehended with crucial intervals in the sketching process. Such analysis provides a deeper understanding of designs and processes that lead to these designs. Furthermore, eye tracking and variations in head positions and focal points in space have been used to evaluate designers' experiences in the virtual reality environment (Rieuf et al., 2015). This approach analyses viewpoints as part of an extensive evaluation of virtual reality immersive moodboards, comparing them to traditional moodboards. Behavioural results indicate that designers have a tendency to distribute their gaze in the immersive condition. In particular, distribution of gaze over an object and a greater number of head movements play a role in immersive conditions.

\subsection{The importance of 'how'}

It is important to analyse how a user's eyes and attention focus on a product because this mechanism influences user impressions of and feelings towards a product. These impressions may fundamentally influence a product's design, use, and overall success. Products that have qualities to connect with human feelings also influence the design, use, and success of future products. Such products expand inner human feelings ${ }^{1}$ and further motivate people to design creative products (Taura and Nagai, 2012). We consider that user preference for a product is connected with the way impressions are formed. User preferences are observed through user ratings. Preference is seen as fundamental for a user's attitude towards a product; further, it is related to imagination about product uses, creativity, and idea generation (ideas about new products [Taura and Nagai, 2012]). Research indicates that the conceptual ideation process is generated from mindsets and stimuli that are intertwined (Junaidy et al., 2015). To address how an impression is formed from a certain product, we examined how products were viewed by focusing on how (dynamically) viewpoints changed. Generally, when a user examines a product, his/her focus is dynamic, as expressed in eye movements. The user's changes in focal points as he/she examines the product, as well as how the user moves the product, are important. The viewpoint can be the same, but the user can try to see different aspects of the product from this viewpoint. Previous studies focused mostly on the examination of unchanging viewpoints, emphasising where, which point, and which part of the product. In this study, however, we were interested in dynamics: moving and changing viewpoints. How the observer dynamically changes and transfers viewpoints is interesting, especially according to the above considerations, since the changes are possibly indications of how impressions and ideas from examination of the product are generated. Methodologically, it is particularly interesting to detect changes in viewpoints when there are no changes in the user's physical position or gaze.

\footnotetext{
${ }^{1}$ Inner feelings are used to express something that exists deep in one's mind.
} 
G. V. Georgiev, K. Yamada and T. Taura

\section{Framework}

\subsection{Definitions}

In this study, we introduce the following definitions.

- Dynamics of shifting viewpoints involves shifts between still viewpoints and moving viewpoints.

- If, in a given period for product observation, the viewpoint does not change, it is defined as a still viewpoint (i.e. there are no shifts in the ways products are viewed).

- A moving viewpoint is defined as a given period for product observation when there are shifts in the way a product is viewed.

- Verbal features involve quantitative characteristics of verbalisations.

The distinction between still and moving viewpoints is useful for a situation in which the physical viewpoint of the user remains the same as different parts of a product become focal points. The interest in the dynamics of shifting viewpoints is the main point of this study. The effects of these dynamics and how they relate to user impressions gained from the product is an interesting direction for investigation.

\subsection{Purpose}

The purpose of this study is to investigate the mechanism of user preferences for products as well as impressions of products by focusing on the dynamics of shifting viewpoints and verbal features in order to inform the design of future products. Our hypothesis is that there will be a positive correlation between user preferences, dynamics of shifting viewpoints, and verbal features. For users, products that they build preferences for may attract their attention, inducing more thoughts about and dynamic examinations of products. This hypothesis is related also to the connections between novelty and interest (Yoon, 2010) and between novelty and aesthetic preference (Hung and Chen, 2012). We considered that users would have more still and moving viewpoints (dynamics of shifting viewpoints), as well as more verbalisations (verbal features), regarding products they preferred.

Preferred products may trigger imagination and creativity. We considered the products from a broad view in the pre-design stage that occurs prior to the starting point of the actual design process. That is to say, we focused on how existing products influence the pre-design stage, in which an understanding of the mechanism of user preferences is fundamental for the creation of new products.

\subsection{Dynamics of shifting viewpoints, verbal features, and preferences}

We have introduced a framework for impressions of products involving three aspects. During the generation of product impressions, we captured and analysed (1) dynamics of shifting viewpoints, (2) verbal features, and (3) user preferences, as well as relationships between the three, as part of a methodology to investigate the mechanism of user attitudes towards designed products (Figure 2). 
Dynamics of Shifting Viewpoints

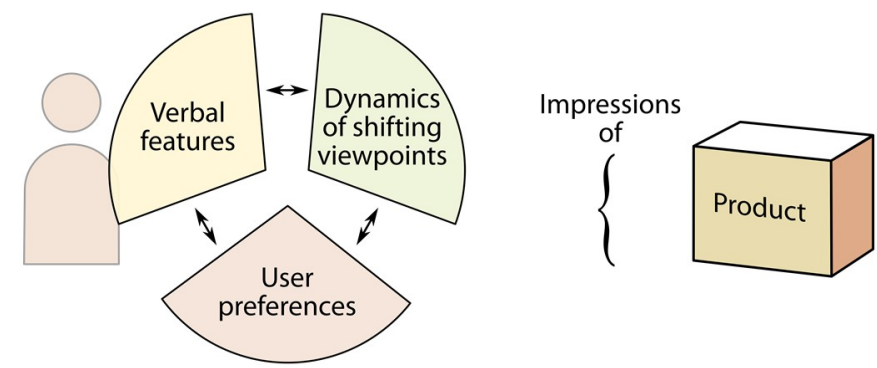

Figure 2. Framework for dynamics of shifting viewpoints, verbal features, and user preferences during the generation of product impressions

\subsection{Capturing the dynamics of shifting viewpoints, verbal features, and user preferences}

In previous studies, users' attitudes towards products have been investigated based on different features exhibited during the generation of user impressions. For example, the movements and fixations of subjects' eyes are indicative of usability issues (Poole and Ball, 2006). However, such movements and fixations are difficult to capture continuously and, consequently, to analyse. Still viewpoints and moving viewpoints-the terms defined in this paper and discussed in the study method below-allow for a simplified framework for the analysis of user preferences for and impressions of a product.

Further, verbalisations and verbal features are related to the generation of impressions and ideas. In addition to regarding verbalisations as a fundamental means of analysing the design process (Chakrabarti et al., 2004), they are also deemed as a means of information for drawing conclusions on perceptions in the case of eye-tracking investigations (Ruckpaul et al., 2014b). Verbalisations are also used to analyse users' feelings (Taura et al., 2010; Junaidy and Nagai, 2013). Additionally, explicit scale ratings are commonly used for examining users' product preferences (Taura et al., 2010; Rieuf et al., 2015).

To investigate the mechanism of users' preferences, we have proposed the following method for capturing and analysing the dynamics of shifting viewpoints and free, unrestricted verbalisations $\mathrm{s}^{2}$ during the generation of impressions of virtual 3D models of products.

\section{Methods}

\subsection{Method for identifying still viewpoints and moving viewpoints}

To capture subjects' still viewpoints and moving viewpoints, we have proposed a method with two characteristics: (1) use of 3D models of products, and (2) interaction of the subject with the product.

These characteristics allowed us to address the purpose of the study and gain deeper insights into viewpoints, compared with previous studies that used two-dimensional images and/or did not allow the subject to change places to look at the product/model.

\footnotetext{
${ }^{2}$ Sometimes verbalizations are restricted (e.g., when a subject is requested to concentrate on a specific problem).
} 


\section{G. V. Georgiev, K. Yamada and T. Taura}

We believe that this method gives the advantage of being closer to the real situation when examining a product, though still allowing for a formalised framework of data capture and analysis (explained further). To capture the viewpoints, we focused on how the virtual 3D model of a product was examined. By observing the manner in which the subject rotates/translates/moves a virtual 3D model (product), we can gain deeper insights into the viewpoints and their role as it relates to user preferences for and impressions of products. In particular, we have proposed a method for analysing subjects' movements of a virtual 3D product model using the operation of a computer mouse. The model was presented using 3D viewing software on a computer screen to allow subjects to look at it from different angles by holding down the left mouse button and moving the mouse. Subjects were also able to view the product closely and from a distance by zooming in and out using the mouse's scroll function.

With this method, a still viewpoint was identified during the period in which the subject did not operate the left mouse button with mouse movement (see Figure 3 from $T_{2}$ to $T_{3}$ ), and a moving viewpoint was identified during the period in which the subject did operate the mouse to move the model (Figure 3 from $T_{1}$ to $T_{2}$ and from $T_{3}$ to $T_{4}$ ). In practical terms, a still viewpoint—noted in the interim period after the subject stopped movement to examine the model and before he/she resumed moving it-was determined using screen video recordings with one-second precision. We also identified a still viewpoint when a zoom-in and zoom-out (using the scroll wheel) occurred without movement (using the left mouse button) in a given period.

\subsection{Quantitative parameters of still viewpoints and moving viewpoints}

Herein, we identify the parameters that could quantitatively describe still viewpoints and moving viewpoints.

We tried to keep the number of variables as small as possible. The length, number, and frequency of still viewpoints and moving viewpoints describe how products are viewed during the generation of impressions. The parameters that quantitatively describe still viewpoints are defined in Table 1, and the parameters that quantitatively describe moving viewpoints appear in Table 2.

Still viewpoints longer than three or more seconds were not considered because of the infrequency with which they were exhibited among subjects. The number of moving viewpoints was not considered because the experimental observation process comprised still viewpoints and moving viewpoints, so their numbers were connected. For practical reasons, the operations were considered to have started with still viewpoints from the initial moment the subject put his/her hand on the mouse to and ended the moment the subject removed his/her hand from the mouse.

\subsection{Method for analysing verbal features and user preferences}

Analysis of verbalisation is common method used to investigate users in cases such as human-computer interaction (HCI) (Nielsen et al., 2002) or in interactions with products (Taura and Nagai, 2012). Here, we focus on the manifest content of verbalisations. We consider their quantitative characteristics, the number of words, and their uniqueness or repetitions as indicative of a user's attitude towards a product. This view is grounded in previous works (Junaidy et al., 2015). 


\section{Dynamics of Shifting Viewpoints}

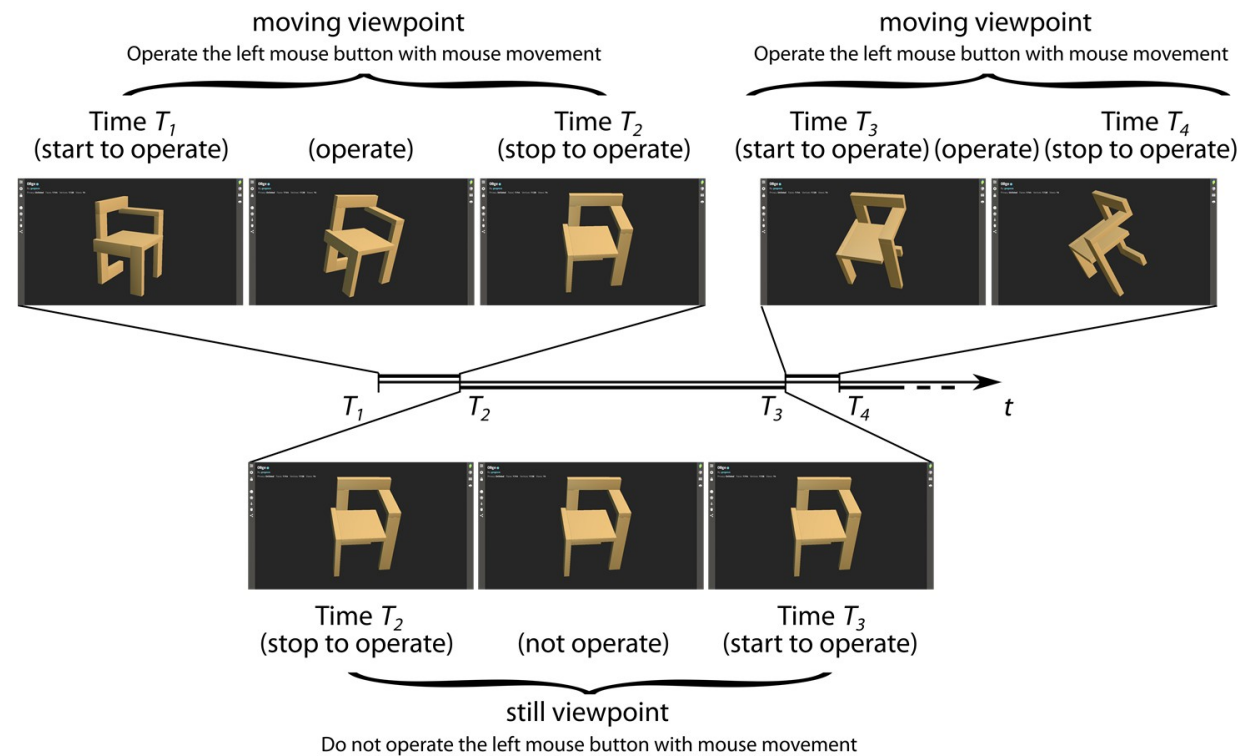

Figure 3. Example of the identification of still viewpoints and moving viewpoints

Table 1. The parameters that quantitatively describe the still viewpoints

\begin{tabular}{|l|l|}
\hline Parameter & Defined as \\
\hline $\begin{array}{l}\text { 'duration of still } \\
\text { viewpoints' }\end{array}$ & $\begin{array}{l}\text { the total amount of time occupied by the still viewpoints during the given } \\
\text { time period in which the subject was asked to view the model }\end{array}$ \\
\hline $\begin{array}{l}\text { 'number of still } \\
\text { viewpoints' }\end{array}$ & $\begin{array}{l}\text { the quantity of still viewpoints (those longer than one second) observed } \\
\text { during the given time period in which the subject was asked to view the } \\
\text { model }\end{array}$ \\
\hline $\begin{array}{l}\text { 'number of still } \\
\text { viewpoints longer } \\
\text { than 2 s' }\end{array}$ & $\begin{array}{l}\text { the quantity of still viewpoints with a duration of more than two seconds } \\
\text { during the given time period }\end{array}$ \\
\hline $\begin{array}{l}\text { 'average length of } \\
\text { still viewpoints' }\end{array}$ & the average duration of each still viewpoint during the given time period \\
\hline
\end{tabular}

Table 2. The parameters that quantitatively describe the moving viewpoints

\begin{tabular}{|l|l|}
\hline Parameter & Defined as \\
\hline $\begin{array}{l}\text { 'duration of moving } \\
\text { viewpoints' }\end{array}$ & $\begin{array}{l}\text { the total amount of time occupied by moving viewpoints during the given } \\
\text { time period in which the subject was asked to view the model }\end{array}$ \\
\hline $\begin{array}{l}\text { 'number of moving } \\
\text { viewpoints longer } \\
\text { than 2 s' }\end{array}$ & $\begin{array}{l}\text { the quantity of moving viewpoints with a duration of more than two seconds } \\
\text { during the given time period }\end{array}$ \\
\hline $\begin{array}{l}\text { 'average length of } \\
\text { moving viewpoints' }\end{array}$ & the average duration of each moving viewpoint during the given time period \\
\hline
\end{tabular}

To count the number of words in users' impressions, verbal protocols observed as the subjects viewed the models were transcribed. Subjects' speech was analysed with a morphological parser, and a list of individual words indicating parts of speech was generated as the output. The verbal features were counted based on this list. The verbal features - the basic quantitative parameters of the verbal protocols- that were considered 


\section{G. V. Georgiev, K. Yamada and T. Taura}

were the 'total number of words' and the number of individual parts of speech ('number of nouns', 'number of verbs', 'number of auxiliary verbs', 'number of adjectives', 'number of adverbs', and 'number of interjections'). The general consideration was that the types of words in the verbalisations could provide insight into user preferences and the generation of ideas. Furthermore, the 'number of repeated words', 'number of word repetitions', and 'number of unique words' were considered indicative of the generation of ideas. The general thought was that the repetition and uniqueness of words in the verbalisations could provide insight into the generation of original ideas linked to user preferences.

User preferences were observed from written ratings on five-point semantic differential (SD) scales (e.g. Dislike-Like, Not original-Original).

\section{Study}

\subsection{Design of the study}

Applying the aforementioned methodology, we conducted an experimental observation of the within-subject type. The setting focused on differences between products that were more or less preferred by a particular subject. We used virtual 3D models of chairs as products. The choice of chairs was based on the consideration that chairs are common everyday products. They have similar spatial configurations and proportions; thus, those aspects should have less influence on the way in which a product is examined. During the experimental observation, virtual 3D models of five chairs (Figure 4) were presented in random order to each of the six subjects in the study (male fourth-year mechanical engineering students). These five models were selected from a larger set of 21 models based on a preliminary questionnaire administered to six other subjects. The preliminary questionnaire contained a simplified rating with three possible answers: like, dislike, and neither.
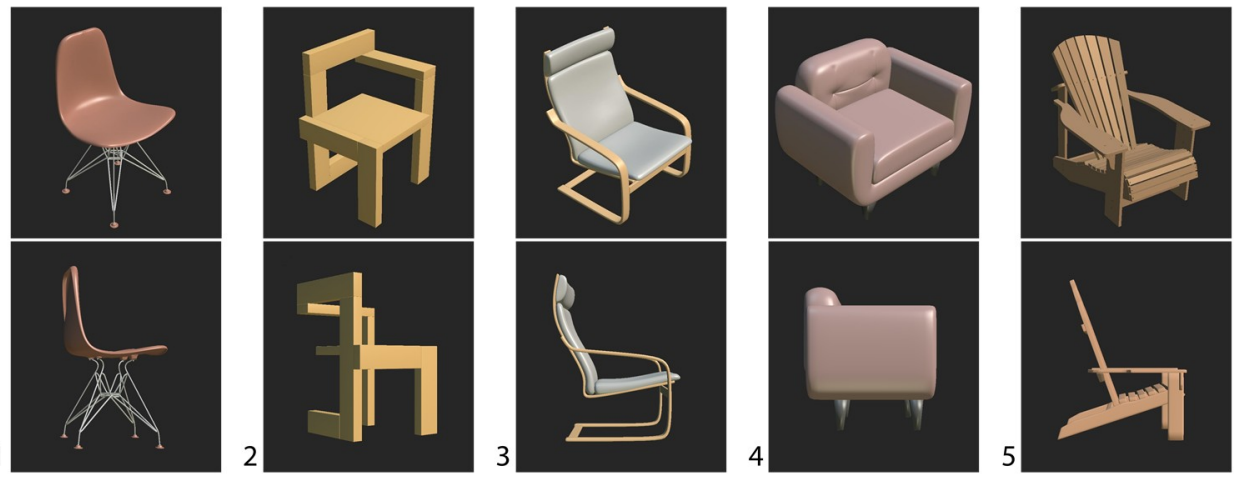

Figure 4. Two example views (side and isometric) of the virtual 3D models of five chairs (Note: all models were obtained from website blendswap.com and attributed with Creative Commons CC0 Zero attribution license. Model 1 can be identified as based on the Eiffel Base Shell Chair by Charles and Ray Eames; Model 2 is based on the Steltman Chair by Gerrit Rietveld; Model 3 is based on the Poäng Chair; and Model 5 is based on the Seashell Adirondack Chair by Thomas Lee. No particular basis could be identified for Model 4. These bases were unknown to the subjects.) 


\section{Dynamics of Shifting Viewpoints}

The five models that were chosen represented the two most disliked and three most liked of the original 21. One of the main considerations in selecting only five chairs was the possibility of the subjects getting bored, tired, or distracted in the examination of a larger number of models. In particular, a large number of models may lead to fewer verbalisations.

\subsection{Setting and procedure}

The virtual 3D models were displayed on a computer screen in front of the subjects, who were each given a computer mouse with which to freely move the displayed models. The following procedures were used:

- Training session: (a) instructions, including examples and training in how to freely verbalise impressions and thoughts about a product, and (b) training in the use of the virtual 3D model viewer software and examination of a virtual 3D product model ${ }^{3}$ (of a different type than those used in the main session, such as a nightstand lamp) using a mouse. The training session was completed when the subjects were able to verbalise freely and move and examine the virtual 3D model on the screen without difficulty.

- Main session: generation of impressions, free verbalisations, and ratings of randomly presented virtual 3D models of five products. The starting point for the session was the presentation of a side view of the model, as shown in Figure 4; each model was placed in the middle of the computer screen and presented in the same way.

Prior to beginning the main session, we provided the six subjects with the following instructions: 'For at least three minutes, please evaluate the product by operating the model. Consider and freely verbalise your impressions and thoughts about the product you evaluate. Please evaluate the product you examine on the following scales'. In the main session, the subjects were free to view the products and generate impressions for longer than three minutes. At the end of the task, we obtained written ratings of the examined products on SD scales.

\subsection{Data capture and analysis}

During the experimental investigation, data were captured via (a) a screen-capture video and general video of the experimental setting, (b) audio recordings, and (c) written ratings on SD scales. For all models, user preferences were obtained through the subjects' ratings on the five-point SD scales according to the following: Dislike-Like, Not interested in-Interested in, Not practical-Practical, and Not original-Original. Choices for the second, third, and fourth scales were motivated by their relation to the early stage of design (originality and practicality as dimensions of creativity) and the potential to relate to generation of ideas and inform the design of future products.

Using the screen-capture video, timings pertaining to still viewpoints and moving viewpoints were identified, having been manually indicated by video using Idea Transcribe v.2.0 software (Idea Transcribe-Google Sites [2013]). Then, quantitative

${ }^{3}$ The browser-based viewer of website www.p3d.in was used to display the full-screen 3D model. 
parameters of the viewpoints and movements were calculated. The verbal features were counted based on transcribed and analysed verbal protocols.

\section{Results}

When the subjects were considered collectively as a single sample, no correlations between dynamics of shifting viewpoints, verbal features, and user preferences were found. However, significant correlations were found between dynamics of shifting viewpoints, verbal features, and user preferences when the subjects were considered individually. We think the reason for this finding is that preferences are individual according to each subject. Particularly, we were interested in the differences in preference levels of individual subjects towards the chairs. Considering the subjects independently, we conducted a rank correlation analysis (Spearman's rho; between rankings of the variables) of the data. This type of analysis was chosen based on the characteristics of the previously defined quantitative parameters of viewpoints and verbal features.

Figure 5 illustrates cases of significant correlations between dynamics of shifting viewpoints, verbal features, and user preferences. The preliminary analysis of the experimental observation was discussed in previous conference reports (Georgiev et al., 2014; Georgiev et al., 2015). Tables 3 and 4 show all observed cases of significant correlations between dynamics of shifting viewpoints and verbal features. For two-tailed Spearman rank correlations, the values in Tables 3 and 4 do not exceed the critical values. For example, for 'number of still viewpoints' and 'total number of words' (Table 3 ), the Spearman rank correlations were $0.359,0.900,0.154,1,000,0.900$, and 0.100 for S1 to S6, respectively. Only correlations for S2, S4, and S5 were significant, as indicated in Table 3. If we examine the correlation for $\mathrm{S} 2$ in this example, the values for number of still viewpoints/total number of words were 61/673, 71/633, 59/520, 39/394, and 78/870 for Models 1 to 5, respectively.

It should be noted that the relationship of the general parameters of duration of still viewpoints and duration of moving viewpoints with verbal features is based on the fact that a longer period will result in more viewpoints and more verbalisations. Since this point does not provide insights, it will not be discussed in further detail. However, the parameters of duration of still viewpoints and duration of moving viewpoints do provide insights in terms of user preferences.

Table 5 shows all observed cases of significant correlations between preferences on the four scales and the verbal features/dynamics of shifting viewpoints. 


\section{Dynamics of Shifting Viewpoints}

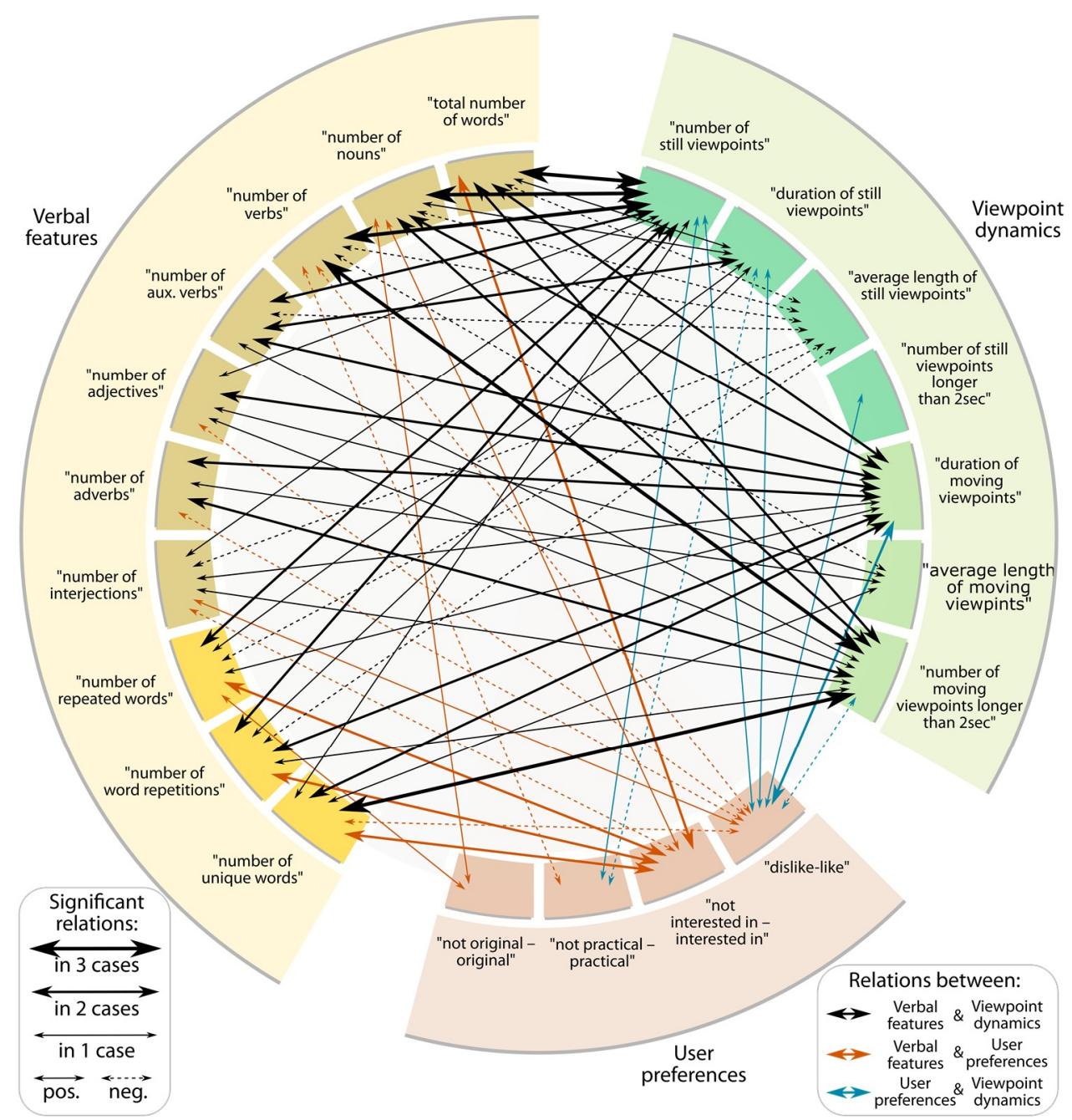

Figure 5. Connections between dynamics of shifting viewpoints, verbal features, and user preferences (Note: Thicker lines indicate that connections are observed in more cases. Continuous lines indicate positive correlations and dotted lines negative correlations.)

Table 3. Significant Spearman rank correlations between dynamics of shifting viewpoints (parameters of still viewpoints) and verbal features

\begin{tabular}{|l|l|l|l|l|}
\hline & $\begin{array}{l}\text { number of still } \\
\text { viewpoints }\end{array}$ & $\begin{array}{l}\text { duration of still } \\
\text { viewpoints }\end{array}$ & $\begin{array}{l}\text { number of still } \\
\text { viewpoints } \\
\text { longer than 2 s }\end{array}$ & $\begin{array}{l}\text { average length of } \\
\text { still viewpoints }\end{array}$ \\
\hline $\begin{array}{l}\text { total number of } \\
\text { words }\end{array}$ & $\begin{array}{l}\mathrm{S} 2: 0.900^{*} \\
\mathrm{~S} 4: 1.000^{* *} \\
\mathrm{~S} 5: 0.900^{*}\end{array}$ & $\mathrm{~S} 4: 0.900^{*}$ & - & $\underline{\mathrm{S} 2:-0.900^{*}}$ \\
\hline number of nouns & $\begin{array}{l}\mathrm{S} 2: 1.000^{* *} \\
\mathrm{~S} 4: 1.000^{* *}\end{array}$ & $\mathrm{~S} 4: 0.900^{*}$ & - & $\underline{\mathrm{S} 2:-1.000^{* *}}$ \\
\hline $\mathrm{S} 5: 0.900^{*}$ & & & \\
\hline
\end{tabular}


G. V. Georgiev, K. Yamada and T. Taura

\begin{tabular}{|l|l|l|l|l|}
\hline number of verbs & $\begin{array}{l}\mathrm{S} 2: 0.975^{* *} \\
\mathrm{~S} 4: 0.900^{*} \\
\mathrm{~S} 5: 0.900^{*}\end{array}$ & - & - & $\underline{\mathrm{S} 2:-0.975^{* *}}$ \\
\hline $\begin{array}{l}\text { number of } \\
\text { auxiliary verbs }\end{array}$ & $\begin{array}{l}\mathrm{S} 2: 1.000^{* *} \\
\mathrm{~S} 4: 1.000^{* *}\end{array}$ & $\begin{array}{l}\mathrm{S} 3: 0.900^{*} \\
\mathrm{~S} 4: 0.900^{*}\end{array}$ & $\mathrm{~S} 3: 1.000^{* *}$ & $\underline{\mathrm{S} 2:-1.000^{* *}}$ \\
\hline $\begin{array}{l}\text { number of } \\
\text { adjectives }\end{array}$ & $\mathrm{S} 5: 0.900^{*}$ & - & - & - \\
\hline $\begin{array}{l}\text { number of } \\
\text { adverbs }\end{array}$ & - & - & - & - \\
\hline $\begin{array}{l}\text { number of } \\
\text { interjections }\end{array}$ & $\mathrm{S} 2: 0.900^{*}$ & - & - & $\underline{\mathrm{S} 2:-0.900^{*}}$ \\
\hline $\begin{array}{l}\text { number of } \\
\text { repeated words }\end{array}$ & $\begin{array}{l}\mathrm{S} 2: 0.975^{* *} \\
\mathrm{~S} 4: 1.000^{* *}\end{array}$ & $\mathrm{~S} 4: 0.900^{*}$ & - & $\underline{\mathrm{S} 2:-0.975^{* *}}$ \\
\hline $\begin{array}{l}\text { number of word } \\
\text { repetitions }\end{array}$ & $\begin{array}{l}\mathrm{S} 2: 0.900^{*} \\
\mathrm{~S} 4: 1.000^{* *}\end{array}$ & $\mathrm{~S} 4: 0.900^{*}$ & - & $\underline{\mathrm{S} 2:-0.900^{*}}$ \\
\hline $\begin{array}{l}\text { number of } \\
\text { unique words }\end{array}$ & $\mathrm{S} 5: 0.900^{*}$ & - & - & - \\
\hline
\end{tabular}

(Note: Subjects are indicated with the letter S and a number, e.g. S1. Negative correlations are underlined for easy identification. Only significant correlations are indicated as follows: *p $<0.05$; $* * \mathrm{p}<0.01)$

Table 4. Significant Spearman rank correlations between dynamics of shifting viewpoints (parameters of moving viewpoints) and verbal features

\begin{tabular}{|c|c|c|c|}
\hline & $\begin{array}{l}\text { duration of moving } \\
\text { viewpoints }\end{array}$ & $\begin{array}{l}\text { number of moving } \\
\text { viewpoints longer than } 2 \mathrm{~s}\end{array}$ & $\begin{array}{l}\text { average length of } \\
\text { moving viewpoints }\end{array}$ \\
\hline $\begin{array}{l}\text { total number of } \\
\text { words }\end{array}$ & $\begin{array}{l}\mathrm{S} 2: 1.000^{* *} \\
\mathrm{~S} 5: 1.000^{* *}\end{array}$ & $\begin{array}{l}\text { S2:1.000** } \\
\text { S5:0.975** }\end{array}$ & - \\
\hline number of nouns & $\begin{array}{l}\mathrm{S} 2: 0.900^{*} \\
\mathrm{~S} 5: 1.000^{* *}\end{array}$ & $\begin{array}{l}\text { S2:0.900* } \\
\text { S5:0.975** }\end{array}$ & - \\
\hline number of verbs & $\begin{array}{l}\text { S2:0.975** S4:0.900* } \\
\text { S5:1.000** }\end{array}$ & $\begin{array}{l}\mathrm{S} 2: 0.975 * * \mathrm{~S} 4: 0.900 * \\
\text { S5:0.975** }\end{array}$ & $\underline{\text { S1:- }-0.900 *}$ \\
\hline $\begin{array}{l}\text { number of } \\
\text { auxiliary verbs }\end{array}$ & $\begin{array}{l}\text { S2:0.900* } \\
\text { S5:0.900* }\end{array}$ & S2:0.900* & - \\
\hline $\begin{array}{l}\text { number of } \\
\text { adjectives }\end{array}$ & $\begin{array}{l}\text { S2:0.900* } \\
\text { S3:0.949* }\end{array}$ & S2:0.900* & S2:0.900* \\
\hline $\begin{array}{l}\text { number of } \\
\text { adverbs }\end{array}$ & $\begin{array}{l}\text { S2:0.900* } \\
\text { S4:0.975** }\end{array}$ & $\begin{array}{l}\text { S2:0.900* } \\
\text { S5:0.921* }\end{array}$ & S2:0.900* \\
\hline $\begin{array}{l}\text { number of } \\
\text { interjections }\end{array}$ & $\mathrm{S} 2: 1.000 * *$ & $\mathrm{~S} 2: 1.000 * *$ & - \\
\hline $\begin{array}{l}\text { number of } \\
\text { repeated words }\end{array}$ & S5:0.900* & - & - \\
\hline $\begin{array}{l}\text { number of word } \\
\text { repetitions }\end{array}$ & $\begin{array}{l}\text { S2:1.000** } \\
\text { S5:0.900* }\end{array}$ & $\mathrm{S} 2: 1.000 * *$ & - \\
\hline $\begin{array}{l}\text { number of } \\
\text { unique words }\end{array}$ & $\begin{array}{l}\text { S2:0.900* } \\
\text { S5:1.000** }\end{array}$ & $\begin{array}{l}\mathrm{S} 2: 0.900 * \mathrm{~S} 4: 1.000 * * \\
\mathrm{~S} 5: 0.975 * *\end{array}$ & S2:0.900* \\
\hline
\end{tabular}

(Note: Subjects are indicated with the letter and a number. Negative correlations are underlined for easy identification. Only significant correlations are indicated as follows: *p $<0.05$; ** $<0.01$ ) 


\section{Dynamics of Shifting Viewpoints}

Table 5. Significant Spearman rank correlations between user preferences and verbal features/dynamics of shifting viewpoints

\begin{tabular}{|c|c|c|c|c|}
\hline & Dislike - Like & $\begin{array}{l}\text { Not interested in } \\
\text { - Interested in }\end{array}$ & $\begin{array}{l}\text { Not practical - } \\
\text { Practical }\end{array}$ & $\begin{array}{l}\text { Not original - } \\
\text { Original }\end{array}$ \\
\hline $\begin{array}{l}\text { total number of } \\
\text { words }\end{array}$ & - & $\begin{array}{l}\text { S1:1.000** } \\
\text { S6:0.975* }\end{array}$ & - & - \\
\hline number of nouns & - & S6:0.975** & - & S1:0.949* \\
\hline number of verbs & S4:0.949* & - & $\underline{\text { S6:-0.949* }}$ & - \\
\hline $\begin{array}{l}\text { number of } \\
\text { adjectives }\end{array}$ & S5:-0.949* & - & - & - \\
\hline number of adverbs & $\underline{\text { S4:- } 0.973 * *}$ & - & - & - \\
\hline $\begin{array}{l}\text { number of } \\
\text { interjections }\end{array}$ & S1:0.892* & $\underline{\text { S5:-0.892* }}$ & - & - \\
\hline $\begin{array}{l}\text { number of repeated } \\
\text { words }\end{array}$ & - & $\begin{array}{l}\text { S1:0.949* } \\
\text { S6:0.975* }\end{array}$ & - & S3:0.982* \\
\hline $\begin{array}{l}\text { number of word } \\
\text { repetitions }\end{array}$ & - & $\begin{array}{l}\text { S1:0.900* } \\
\text { S6:0.975** }\end{array}$ & - & - \\
\hline $\begin{array}{l}\text { number of unique } \\
\text { words }\end{array}$ & $\underline{\text { S4:-0.949* }}$ & $\begin{array}{l}\text { S1:0.975** } \\
\text { S6:0.975** }\end{array}$ & - & - \\
\hline $\begin{array}{l}\text { number of still } \\
\text { viewpoints }\end{array}$ & S1:0.892* & - & S1:0.947* & - \\
\hline $\begin{array}{l}\text { duration of still } \\
\text { viewpoints }\end{array}$ & S1:0.949* & - & - & - \\
\hline $\begin{array}{l}\text { number of still } \\
\text { viewpoints longer } \\
\text { than } 2 \mathrm{~s}\end{array}$ & S1:0.892* & - & S1:0.947* & - \\
\hline $\begin{array}{l}\text { average length of } \\
\text { still viewpoints }\end{array}$ & - & - & $\underline{\mathrm{S} 1: 0.975 * *}$ & - \\
\hline $\begin{array}{l}\text { duration of moving } \\
\text { viewpoints }\end{array}$ & $\begin{array}{l}\underline{\text { S4:-0.949* }} \\
\underline{\text { S6:-0.949* }} \\
\end{array}$ & - & - & - \\
\hline $\begin{array}{l}\text { number of moving } \\
\text { viewpoints longer } \\
\text { than } 2 \mathrm{~s}\end{array}$ & $\underline{\text { S4:-0.949* }}$ & - & - & - \\
\hline
\end{tabular}

(Note: Subjects are indicated with the letter and a number. Rows of number of auxiliary verbs and average length of moving viewpoints are omitted due to lack of correlations. Negative correlations are underlined for easy identification. Only significant correlations are indicated as follows: * $p<$ $0.05 ; * * \mathrm{p}<0.01)$

The temporal characteristics of the viewing and impressions sessions, as well as sequences of still viewpoints and moving viewpoints - with their lengths - , are shown in Figure 6. The temporal characteristics provide a general overview of the sequences and indicate where there are longer periods of still and moving viewpoints. In particular cases, a nearly regular pattern of periods of similar length can be observed, whereas in other cases, more diversity in length can be seen (e.g. Subject 1 [S1] and model 2, or S4 and model 3). 

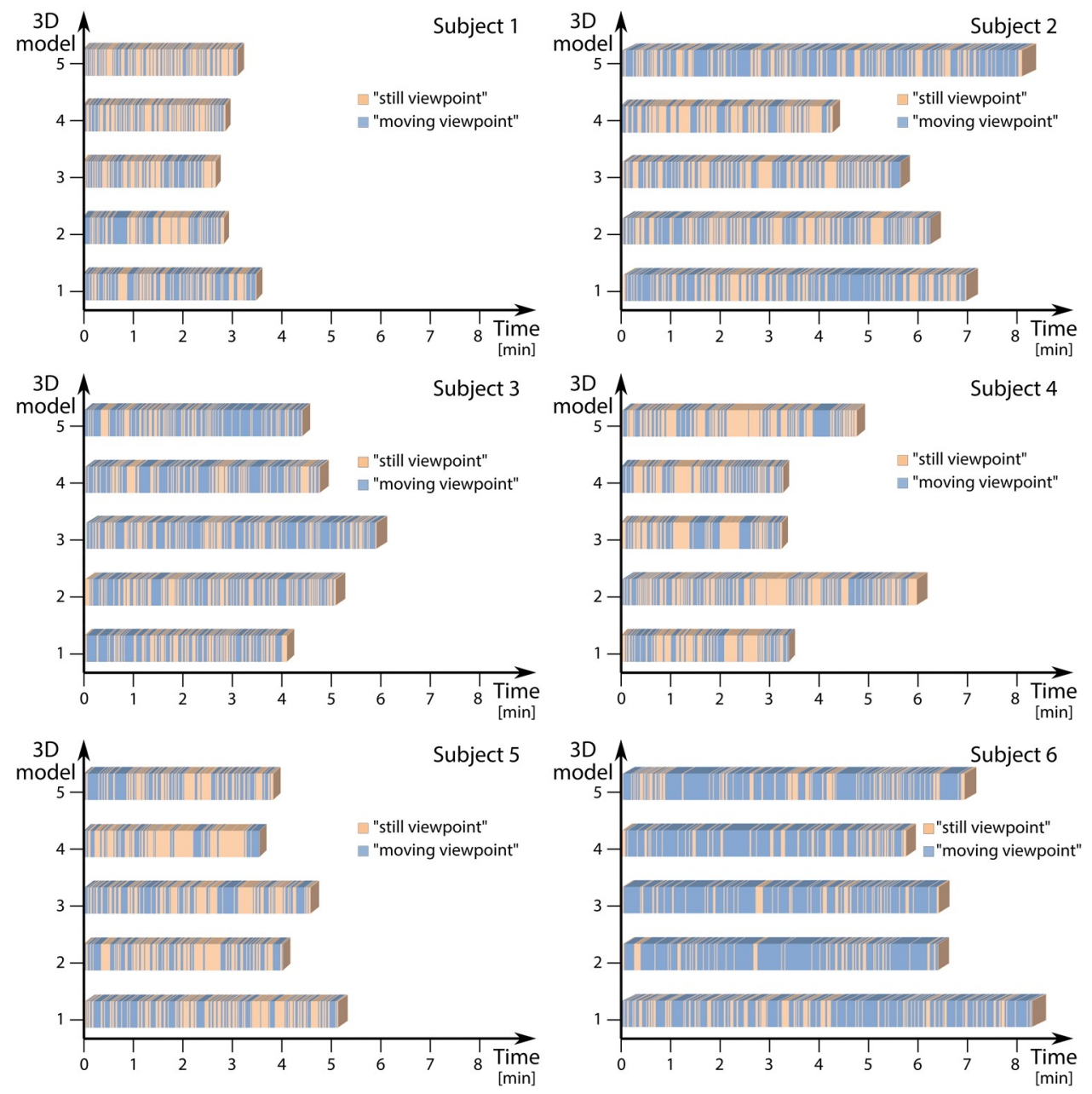

Figure 6. Temporal characteristics (Note: some of the short time periods are not visible because of resolution limitations of the figure)

We examined some utterances corresponding to the cases of correlations. Such can be identified based on Figure 6. For example, a high number of moving viewpoints can be identified for Subject 2, Model 2, beginning at 01:45. The utterance at this point and at other points relevant to the correlations are shown in Table 6.

Table 6. Examples of verbalisations.

\begin{tabular}{|l|l|}
\hline \multicolumn{2}{|l|}{ Relation verbal features - dynamics of shifting viewpoints ('number of still viewpoints') } \\
\hline Subject & Model (time): 'Verbalisation' \\
\hline S2 & $\begin{array}{l}\text { Model 2 (01.45 ): 'Well, well, when I look at the chair, it is novel as structure. } \\
\text { Although, thinking, when actually using it, the backrest is angular.' } \\
\text { Model 3 (04.20 ): 'I feel it is cheap and I wish I could buy it. Well, as well as an } \\
\text { image...' }\end{array}$ \\
\hline S4 & $\begin{array}{l}\text { Model 2 (00.20 ): 'Here, no... This is the strangest design I have seen. I do not know } \\
\text { how to sit down. I do not know whether it is a chair or not.' }\end{array}$ \\
\hline
\end{tabular}




\begin{tabular}{|c|c|}
\hline S5 & $\begin{array}{l}\text { Model } 1 \text { (02.30 ): 'Because the seating surface is so wide. A little strange, like a little } \\
\text { rhombus when looking as a whole...' } \\
\text { Model } 5 \text { (02.40 ): 'I do not feel like having it. That is right, I guess it is not that } \\
\text { practical.' }\end{array}$ \\
\hline \multicolumn{2}{|r|}{$\begin{array}{l}\text { Relation verbal features - dynamics of moving viewpoints ('number of moving viewpoints longer } \\
\text { than } 2 \mathrm{~s} \text { ') }\end{array}$} \\
\hline $\mathrm{S} 2$ & $\begin{array}{l}\text { Model } 1 \text { (04.10 ): 'It seems small. Well, very well. I wonder if I can buy it cheaply.' } \\
\text { Model } 5 \text { (03.30 ): 'Well, I have that kind of feeling, because there are gaps. Well, } \\
\text { because there are gaps, things can pass through. Wind also passes.' }\end{array}$ \\
\hline S4 & $\begin{array}{l}\text { Model } 5 \text { (01.10 ): 'I think in this chair I can sleep comfortably and pleasantly. Wood... } \\
\text { is wood used? I guess it elongates somewhere.' }\end{array}$ \\
\hline S5 & $\begin{array}{l}\text { Model } 3 \text { (00.10 ): 'Feeling like simple, simple chair. Something, it feels like I have } \\
\text { seen such form. Looks wobbly to recline.' }\end{array}$ \\
\hline
\end{tabular}

\section{Discussion}

\subsection{Dynamics of shifting viewpoints and verbal features}

The number of still viewpoints was connected to the number of verbal features, possibly because the subjects had more time to express themselves verbally when the model was still. However, for several subjects, an interesting observation was that the longer moving viewpoints and shorter still viewpoints both attracted a greater number of verbal features. Additional indicators here are unique and repeated words. Still viewpoints can be associated with repeated words, but moving viewpoints are associated with unique and repeated words. Further, Table 3 shows that the number of still viewpoints correlates positively with most of the verbal features for Subjects 2, 4, and 5. Additionally, there are similar positive correlations regarding 'still viewpoints of longer than $2 \mathrm{~s}$ ' in the cases of Subjects 1 and 3. Notably, the 'number of moving viewpoints longer than $2 \mathrm{~s}$ ' has many positive correlations with verbal features in the cases of Subjects 2, 4, and 5 (with one exception). These correlations outline a picture of the dynamics of shifting viewpoints (longer moving viewpoints) related to more intensive and unique verbalisations (verbal features). Such viewpoints may lead to images and sensations contributing to richer mental imagery (Richardson, 2013). Moreover, findings are in line with the connection of novelty and complexity with interest (Yoon, 2010). It can be speculated that examining products with longer moving viewpoints may be related to more intensive idea generation and more unique ideas. Moving viewpoints can be employed in idea generation. For example, a stimulus presented to a designer that leads to longer moving viewpoints may allow for the generation of more ideas.

Furthermore, the observation can be made that the 'average length of still viewpoints' is negatively correlated with verbal features in the case of Subject 2. Moreover, correlations for the 'average length of moving viewpoints' are inconsistent (both positively and negatively). Cases of verbs, nouns, and many or unique words were most often correlated with the parameters of still viewpoints and moving viewpoints. It should be noted that data for Subject 6 exhibited hardly any correlations, positive or negative, between the parameters included in Figure 5. 


\section{G. V. Georgiev, K. Yamada and T. Taura}

Previously, the combination of thinking aloud and eye tracking was observed in detail (Ruckpaul et al., 2014a), and results showed that the former did not have significant influence on the latter. Here, we may consider the dynamics of shifting viewpoints and verbal features as independent but connected when a product is examined by the user.

\subsection{Dynamics of shifting viewpoints and user preferences}

Regarding the dynamics of shifting viewpoints, for Subject 1, the duration of still viewpoints and number of still viewpoints were connected with higher ratings on the Dislike-Like scale. In contrast, the duration of moving viewpoints for Subjects 4 and 6 was linked with lower ratings. That is to say, a longer duration of still viewpoints and shorter duration of moving viewpoints relate to user preferences. These correlations may point to two complementary aspects of the same process- more and longer still viewpoints relate to higher levels of user preferences, whereas longer moving viewpoints relate to lower levels. The interpretation of these observations is based on the connection of preference with novelty and interest (Yoon, 2010)-hence, with still viewpoints.

The number of eye movements is important for cases of innovative designs (Carbon et al., 2006). An understanding of the dynamics of shifting viewpoints in our study in relation to preferences in an interactive examination of a product is essential for preferences for new and innovative products or product designs (Faerber and Carbon, 2013). Therefore, comprehending the focal points in innovative products and the dynamics between them may be essential for evoking preferences for these products.

Through the framework introduced in our study, we developed a deeper understanding of how the number and duration of viewpoints in a setting close to a realworld interactive situation compared to unchanging images of products when their visually aesthetic qualities were investigated (Khalighy et al., 2015).

\subsection{Verbal features and user preferences}

Few significant correlations between user preferences and verbal features were observed for Subject 1. 'Number of nouns' and 'number of unique words' were found to be negatively related to dislike-like. However, it is not possible to make definitive conclusions because of their basis on a single subject. Verbal features and related parameters exhibit connections with user preferences, but it is noteworthy that the connections are stronger for preferences related to Not interested in-Interested in, which may be an expected result.

\subsection{Wider context, qualitative insights, and implications}

Though the approach we applied was a primary decomposition of the user's viewpoints, findings can be integrated and placed in a wider context in which they are relevant for both users and designers, especially in the role of design of products in the formation of attitudes in users. In practical terms, presentation of a product online or in virtual reality with consideration for moving viewpoints may influence a user's interest, selections, and purchasing decisions. Richer mental imagery could influence the customer appeal of a design output (Dahl et al., 1999). Focusing on the visual sensory experience (Schifferstein, 2009; Elsen and Heylighen, 2014), we gain insights as to how mental imagery about a product is formed because our experimental observation allowed-at 


\section{Dynamics of Shifting Viewpoints}

least partially_for self-conscious awareness and reputability of experienced images and sensations constituting mental imagery (Richardson, 2013). Based on Tables 3 and 4 and Figure 4, the following qualitative insights can be made. In the cases of Subjects 2, 4, and 5 , which exhibit many correlations, qualitatively different dynamics of shifting viewpoints are seen; they are characterised by very long and very short still viewpoints. This observation is also valid to a lesser extent for moving viewpoints. Thus, it can be suggested that such diverse dynamics of shifting viewpoints are indicative of user preferences and contribute to the formation of overall attitudes towards products and the selection of products.

In summary, more and longer still viewpoints relate to higher levels of user preference, which is in line with our hypothesis. However, longer moving viewpoints relate to lower levels of user preference. It is possible to assert that numerous, short still viewpoints are complemented by moving viewpoints over time; in other words, dynamics of shifting viewpoints are related to more (quantitatively) verbalisations (verbal features), including unique ones. Thus, user preference may reflect the dynamics of shifting viewpoints, which independently relate to verbal features. However, user preference and verbal features are not strongly connected. Furthermore, the dynamics of shifting viewpoints may be related to the generation of user impressions, as well as to design idea generation and design creativity. Potential seeds can be found in cognitive dissonance during conceptualisation at the early stage of idea generation; moreover, capturing and utilising stimuli during extreme levels of cognitive fixedness that produce conflicts of stimuli may lead to unconventional ways of thinking (Junaidy et al., 2015).

Qualitative insights can be gained on the basis of the verbalisations. On one side, regarding the dynamics of shifting viewpoints, terms such as 'novel', 'strange', and 'not practical' can be identified in connection with higher numbers of still viewpoints. On the other side, regarding the number of moving viewpoints longer than 2 seconds, words related to feelings can be identified (e.g. 'feeling, 'comfortable', or 'pleasant'). It can be speculated that moving viewpoints contribute to richer mental imagery, which is related to feelings (Richardson, 2013; Schifferstein, 2009).

The overall goal of this research was to understand the mechanism of users' preferences for and impressions of products and how they are related, with the aim of informing the design of preferred products. The results provide relevant insights about this mechanism. The implications relate to the generation of ideas in general and original ideas in particular, based on the connection of originality/novelty with interest (Yoon, 2010) and on richer mental imagery (Richardson, 2013) that may result from the dynamic shifting of viewpoints. Implications can be sought for the potential use of products presented in a particular way as inspirations or stimuli for idea generation. The use of multiplicity (the polysemy of viewpoints) and dynamics of shifting viewpoints as tools, therefore, may influence creativity in design in a positive way.

However, the observations in this study can be regarded as exploratory, demonstrating the connections between verbal features, dynamics of shifting viewpoints, and preferences during the generation of product impressions. This is not a strong validation, and experiments that are more extensive must be conducted to gain insights into the mechanism of user attitudes towards products. 


\section{G. V. Georgiev, K. Yamada and T. Taura}

\subsection{Limitations}

This study has several limitations. First, the methodology was focused on collecting highlevel data, and the impressions generated from the use of 3D product models may differ from those generated by interaction with real products. Virtual models may differ from physical products in terms of interactions. However, the methodology allowed for the free generation of impressions in accordance with subjects' feelings. Second, our exploratory study was limited in terms of the number and types of products and subjects; this issue must be addressed in the future. Third, in this study, we investigated only one aspect of the way in which products are viewed. Approaches that incorporate other aspects of viewing may provide deeper insights into the issue. Gathering other types of data for which the focus is on user attention is recommended for further investigation. The viewpoint whereby the user is 'looking without seeing' (Matthiesen et. al., 2013) is pointed out as very difficult to analyse. In this study, we did not analyse it. Fourth, this study was primarily quantitative; thus, a limitation is that it mostly concerns manifest content of verbalisations (i.e. number of times certain types of words are used), with limited qualitative analysis of content.

\subsection{Future directions}

In particular, future work should aim at delving deeper into the dynamics of shifting viewpoints in relation to verbalisations, thereby focusing on the qualitative aspect of such verbalisations. In future work, it may be possible to describe qualitatively different patterns in behaviour with regard to the dynamics of shifting viewpoints. The aforementioned findings provide a basis for the further investigation of the generation of ideas and the multiplicity of viewpoints and verbalisations - the polysemy of meanings. The logical step after the discussion in the above sections is to establish future hypotheses in order to further investigate the dynamics of shifting viewpoints. These hypotheses may aim at the investigation of multiplicity (polysemy) of viewpoints in different stages of ideation about products and related design processes. One such hypothesis could be the following: Dynamics of shifting viewpoints in the early stages of design relate to the originality and creativity of the generated design ideas. We believe that the polysemy of user impressions can be expressed in relation to the dynamics of shifting viewpoints that appear during interactions with a given product.

\section{Conclusions}

In this study, we hypothesised that user preferences and impressions are connected with the way in which a product is observed in order to explore the mechanisms associated with user preferences for and impressions of products. We considered that user preferences were related to the dynamics of shifting viewpoints and verbal features emerging during the generation of product impressions. The findings from an experimental observation in which virtual 3D models of products were employed showed that, in many cases, quantitative characteristics of the dynamics of shifting viewpoints were related to quantitative increases in subjects' verbalisations, as well as other verbal features, including unique verbalisations. Thus, the dynamics of shifting viewpoints and verbal features may reflect user preferences, the generation of user impressions, and 


\section{Dynamics of Shifting Viewpoints}

overall attitudes towards products. Such knowledge can inform the design of preferred products.

\section{Acknowledgement}

This work was supported by JSPS KAKENHI Grant Number 25750001.

\section{References}

Albarracin, D., Wang, W., Li, H., and Noguchi, K. (2008) Structure of attitudes: Judgments, memory, and implications for change. In Crano, W.D. and Prislin, R. (Eds.) Attitudes and Attitude Change, New York: Psychology Press, pp.19-40.

Berlyne, D.E. (1971) Aesthetics and Psychobiology. New York: Appleton-Century-Crofts.

Bongard-Blanchy, K., Bouchard, C., Bonnardel, N., Lockner, D., and Aoussat, A. (2015) 'User experience dimensions in product design: a consolidation of what academic researchers know and what design practitioners do', Journal of Design Research, Vol. 13 No. 2, pp.107-124.

Carbon, C.C., Hutzler, F. and Minge, M. (2006) 'Innovativeness in design investigated by eye movements and pupillometry', Psychology Science, Vol. 48 No. 2, pp.173-186.

Chakrabarti, A., Morgenstern, S. and Knaab, H. (2004) 'Identification and application of requirements and their impact on the design process: a protocol study', Research in Engineering Design, Vol. 15 No. 1, pp. 22-39.

Chen, L.H., Lee, C.F. and Tsai, C.M. (2007) 'Perceiving Affordances through Perceptual Information' in Proceedings of International Association of Science of Design Research 2007 (IASDR07), Hong Kong.

Coates, D. (2002) Watches tell more than time. McGraw-Hill.

Dahl, D.W., Chattopadhyay, A., and Gorn, G.J. (1999) 'The Use of Visual Mental Imagery in New Product Design', Journal of Marketing Research, Vol. 36 No. 1, pp.18-28

Elsen, C., and Heylighen, A. (2014) 'Representations of sensory experiences in the early phases of architectural design: there is more than meets the eye', Journal of Design Research, Vol. 12 No. 4, pp. 239-259.

Faerber, S.J. and Carbon, C.C. (2013) 'Jump on the innovator's train: cognitive principles for creating appreciation in innovative product designs', Research in Engineering Design, Vol. 24 No. 3, pp.313-319.

Fenko, A., Schifferstein, H. N., and Hekkert, P. (2010) 'Shifts in sensory dominance between various stages of user-product interactions', Applied ergonomics, Vol. 41 No. 1, pp. 34-40.

Festinger, L. (1957). Cognitive dissonance. Stanford, CA: Stanford University Press.

Georgiev, G.V., Yamada, K. and Taura, T. (2014) 'An Analysis of Viewpoints during Evaluation of Products' in Poster Proceedings of Sixth International Conference on Design Computing and Cognition (DCC14), London, UK, pp.27-28.

Georgiev, G.V., Yamada, K. and Taura, T. (2015) 'Viewpoint Dynamics and Verbal Features: An Investigation of User Preferences for and Impressions of Products' in Proceedings of the Third International Conference on Design Creativity (3rd ICDC), Bangalore, India, pp.27-34.

Harmon-Jones, E., and Harmon-Jones, C. (2012) 'Cognitive dissonance theory', in Shah, J.Y. and Gardner, W.L. (Eds.), Handbook of motivation science, pp.71-83.

Haug, A. (2015) 'Four dimensions of product designs', Journal of Design Research, Vol. 13 No. 1, pp.20-35.

Hung, W.K., and Chen, L.L. (2012) 'Effects of novelty and its dimensions on aesthetic preference in product design', International Journal of Design, Vol. 6 No.2, pp.81-90.

Idea Transcribe-Google Sites (2013) https://sites.google.com/site/ideatranscribe

Junaidy, D.W. and Nagai, Y. (2013) 'The in-depth cognitive levels of imagination of artisans and designers', Journal of Design Research, Vol. 11 No. 4, pp.317-335. 


\section{G. V. Georgiev, K. Yamada and T. Taura}

Junaidy, D.W., Kaner, J., Ioras, F., and Nagai, Y. (2015) 'Capturing characteristics of the conceptual ideation process of master crafts persons to inform design education: a comparative study of rural craft practitioners in Indonesia and in the UK', Journal of Design Research, Vol. 13 No. 4, pp.395-423.

Khalighy, S., Green, G., Scheepers, C. and Whittet, C. (2015) 'Quantifying the qualities of aesthetics in product design using eye-tracking technology', International Journal of Industrial Ergonomics, Vol. 49, pp.31-43.

Matthiesen, S., Meboldt, M., Ruckpaul, A. and Mussgnug, M. (2013) 'Eye Tracking, a method for engineering design research on engineers' behavior while analyzing technical systems' in Proceedings of International Conference on Engineering Design ICED13, Seoul, Korea.

Nielsen, J., Clemmensen, T. and Yssing, C. (2002) 'Getting access to what goes on in people's heads?: reflections on the think-aloud technique' in Proceedings of the Second Nordic conference on Human-computer interaction (NordiCHI), ACM, Århus, Denmark, pp.101-110.

Poole, A. and Ball, L. J. (2006) 'Eye tracking in HCI and usability research' in Encyclopedia of human computer interaction, Vol. 1, pp.211-219.

Richardson, A. (2013) Mental imagery. Springer.

Rieuf, V., Bouchard, C. and Aoussat, A. (2015) 'Immersive moodboards, a comparative study of industrial design inspiration material', Journal of Design Research, Vol. 13 No.1, pp.78-106.

Ruckpaul, A., Fürstenhöfer, T. and Matthiesen, S. (2014a) 'Combination of Eye Tracking and Think-Aloud Methods in Engineering Design Research', in Gero, J.S. and Hanna, S. (Eds.), Design Computing and Cognition DCC'14, pp.83-101.

Ruckpaul, A., Kriltz, A. and Matthiesen, S. (2014b) 'Using Eye Tracking to Understand the Engineering Designers' Behavior in Synthesis-Driven Analyzing Processes - Experiences In Study Design' in Proceedings of International Conference on Human Behavior in Design, 1417 October 2014, Ascona, Switzerland.

Schifferstein, H. N. (2009) Comparing mental imagery across the sensory modalities. Imagination, Cognition and Personality, Vol. 28, No. 4, pp.371-388.

Sun, L., Xiang, W., Chai, C., Yang, Z. and Zhang, K. (2014) 'Designers' perception during sketching: An examination of Creative Segment theory using eye movements', Design Studies, Vol. 35 No.6, pp.593-613.

Taura, T. and Nagai, Y. (2012) Concept generation for design creativity: A systematized theory and methodology, Springer-Verlag, London.

Taura, T., Yamamoto, E., Fasiha, M.Y.N. and Nagai, Y. (2010) 'Virtual impression networks for capturing deep impressions' in Design Computing and Cognition 10, Springer, pp.559-578.

Toh, C. A. and Miller, S. R. (2014) 'The Impact of Example Modality and Physical Interactions on Design Creativity', Journal of Mechanical Design, Vol. 136 No. 9, 091004-1.

Yoon, J. (2010) 'Experience of interest in human-product interaction', Doctoral dissertation, TU Delft, Delft University of Technology.

Zajonc, R. B. (1980) Feeling and thinking: Preferences need no inferences. American psychologist, Vol. 35, No.2, pp.151-175. 